\title{
INFLUENCE OF HYPERCALCEMIA IN THE TYPE 2 DIABETES
}

Brutskaya - Stempkovskaya E. V.1,2,Shepelkevich A.P1

Belarusian State Medical University ", Minsk city polyclinic N312, Belarus

Introduction: In recent years there have been studied the influence of hypercalcemia on the risk of type 2 diabetes and the status of carbohydrate metabolism in patients with hypercalcaemia.

Objective: to investigate the prevalence of type 2 diabetes in patients with hypercalcemia compared with patients without hypercalcemia.

\section{MATERIALS}

AND

METHODS:

1000 patients from 18 to 96 years:

- the average age: $54,68 \pm 16,96$;

- 727 women;

- 273 men;

Examination:

- total calcium;

- total protein;

- Creatinine;

- cholesterol;

- Triglycerides;

- the analysis of morbidity :

(osteoporosis, kidney stones, cholelithiasis, ulcer disease, type2 diabetes hypertension, coronary heart disease, cardiovascular events, cancer, fractures in history).

\section{CONCLUSION:}

The results of the study have shown an increasing prevalence of type 2 diabetes in patients with hypercalcaemia. The results may indicate the influence of hypercalcemia in the frequency of manifestation of type 2 diabetes.

\section{RESULTS:}

Prevalence Of type 2 diabetes

Group of patients without patients hypercalcaemia hypercalcaemia

The number of

patients

974

26

The number of

type 2 diabetes

118

5

\begin{tabular}{l|l|r|}
\hline$\%$ & 12,1 & 19,2 \\
\hline
\end{tabular}

Significant differences were detected in the prevalence of type 2 diabetes in patients with hypercalcemia and in patients without hypercalcemia $\left(X^{2}=0,57, p<0,0001\right)$. 